\title{
Modeling the binding of peptides on carbon nanotubes and their use as protein and DNA carriers
}

\author{
Vanesa Sanz $^{1,2 \pm^{*}}$, Helen M. Coley ${ }^{1}$, S.Ravi P. Silva ${ }^{2}$ and Johnjoe McFadden ${ }^{1}$ \\ ${ }^{1}$ Faculty of Health and Medical Sciences, University of Surrey \\ Guildford, GU2 7XH (United Kingdom) \\ ${ }^{2}$ Nano-Electronics Centre, Advanced Technology Institute, University of Surrey \\ Guildford, GU2 7XH (United Kingdom) \\ *Corresponding author, e-mail address: vasanz@unizar.es
}

\begin{abstract}
An in deep study of the functionalization of carbon nanotubes for their application as peptides and DNA carriers is presented. Designed amphiphilic polypeptides are used to study the dispersion properties of single-walled carbon nanotubes (SWCNTs) and to measure the properties of the carbon nanotube-polypeptide complexes. These properties allow the design of methods for using carbon nanotubes as platforms for protein and DNA binding. First, a model that characterizes the adsorption of natural peptides onto SWCNTs is developed which allows the design of functionalization methods of SWCNTs with proteins. This model was based on properties that describe the protein structure and composition. Second, the binding of cationic amphiphilic polypeptides to SWCNTs is studied for subsequent and efficient binding of DNA to carbon nanotubes by a bilayer approach. These functionalization methods for the development of protein and DNA carriers have potential applications in using SWCNTs in important fields such as biosensing and delivery systems design.
\end{abstract}

KEYWORDS. Carbon nanotubes, peptides, DNA, biodelivery, biosensor. 


\section{INTRODUCTION}

The development of functionalization methods of carbon nanotubes (CNTs) for applications in the biomedical field has had a considerable interest in recent years. CNTs have been extensively studied in recent years as one of the most promising gene and drug delivery systems (Bianco et al. 2005; Liu et al. 2009) and in biosensing (Kim et al. 2007; Ju et al. 2009; Ziegler 2005). However, naked CNTs are not appropriate for these applications as they are insoluble, so they have first to be functionalized in some way. The properties of the functionalized CNTs are likely to have a profound effect on their ability to enter cells and deliver cargos, as well as affect their toxicological properties when using as delivery vector. Furthermore, the functionalization method affects the optical, electronic and electrochemical properties of CNTs when they are applied in the development of nanoelectronic devices and nanosensors (Chen et al. 2003; Besteman et al. 2003; Kurppa et al. 2007). Several kinds of covalent and non-covalent functionalization methods have been investigated but the non-covalent approach has the significant advantage that it preserves the unique properties of carbon nanotubes (Klumpp et al. 2006). The use of biomolecules such as nucleic acids and proteins as surfactants has the additional advantage of making the functionalized CNTs biocompatible. The use of DNA (Enyashin et al. 2007) and RNA (Jeynes et al. 2006) to disperse carbon nanotubes has been extensively studied. Proteins may also be used to disperse and functionalize CNTs, which may have several advantages over nucleic acid, such as modified immune response (Pantarotto et al. 2003; Salvador-Morales et al. 2006) and ease of further functionalizations (Heister et al. 2009) (e.g. adding additional groups such as fluorescent dyes via amine and sulfide groups). Different procedures for the attachment of proteins to CNTs have been already described. Covalent methods use, for example, the 
diimide-activated amidation of nanotube carrying carboxylic groups after acid treatment (Huang et al. 2002) or the reaction of protein amine groups with a succinimidyl derivative of pyrene adsorbed onto the sidewall of SWCNTs by $\pi$ stacking (Chen et al. 2001). Proteins can also be attached to CNTs by means of the biotin-streptavidin system (Shim et al. 2002). Several studies have been performed on the adsorption of proteins (Kurppa et al. 2007; Karajanagi et al. 2006; Matsuura et al. 2006) and designed peptides (Salzmann et al. 2007; Salzmann et al. 2008; Zorbas et al. 2004) onto carbon nanotubes but no detailed study of the binding characteristics of different forms of protein to CNTs has yet been performed. In this paper, we investigate the use of designed amphiphilic polypeptides to disperse SWCNTs and measure the properties of the SWCNTprotein complexes. These measurements are used to develop a model of the adsorption of proteins onto SWCNTs. As an application of this functionalization, we optimize the binding of amphiphilic polypeptides containing cationic groups to SWCNTs for subsequent and efficient binding of nucleic acids for their potential applications as gene delivery systems.

\section{EXPERIMENTAL}

\subsection{MATERIALS}

SWCNTs were purchased from Sigma ( $>90 \%$ carbon (TGA), 0.7-1.1 nm diameter). The following polypeptides were obtained from Sigma and used in these studies: poly(Lys:Trp, 4:1), poly(Lys:Tyr, 1:1), poly(Arg:Trp, 4:1), poly(Lys:Tyr, 4:1), poly(Orn:Trp, 4:1), poly(Lys:Phe, 1:1) poly(Lys:Tyr, 1:9) and poly(Glu:Lys:Tyr, 6:3:1). Proteins were obtained from Sigma: bovine serum albumin, trypsin from bovine pancreas (T1426), pepsin from porcine gastric mucosa (P6887), lysozyme from chicken egg white (62970), ferritin from equine 
spleen (F4503), fibrinogen from bovine plasma (46312), papain from papaya latex (P3375), haemoglobin from bovine serum. 5(6)-Carboxyfluorescein Nhydroxysuccinimide ester was obtained from Sigma (21878).

\subsection{METHODS}

Functionalization of SWCNTs with amphiphilic polypeptides. The appropriate amount of SWCNT (from $0.15 \mathrm{mg}$ to $2 \mathrm{mg}$ ) were mixed with $1 \mathrm{~mL}$ of the polypeptide of $0.3 \mathrm{mg} \mathrm{mL}^{-1}$ in distilled water and the mixture was ultrasonicated in a Soniprep for $40 \mathrm{~s}$ ( 4 cycles of $10 \mathrm{~s}$ on and $10 \mathrm{~s}$ off) and then sonicated for $2 \mathrm{~h}$ in water bath $(3 \mathrm{~W})$ at room temperature. The suspension was then centrifuged at $13200 \mathrm{rpm}$ for 10 minutes and the supernatant was pippeted off. Excess of polypeptide was removed by ultrafiltration in filters tubes of $100 \mathrm{kDa}$ and washing the retentate 3 times with distilled water. The functionalized SWCNTs were suspended in $1 \mathrm{~mL}$ of distilled water.

Functionalization of SWCNTs with polypeptides chemically modified with fluorescein. First, polypeptides carrying amine groups (lysine side chains of the polypeptide) were chemically modified with a succinimide derivative of fluorescein. Two chemically modified polypeptides were synthesized: poly(Lys:Phe, 1:1) and poly(Glu:Lys:Tyr, 6:3:1). For poly(Lys:Phe, 1:1), $3 \mathrm{~mL}$ of the polypeptide of $2 \mathrm{mgmL}^{-1}$ were mixed with $300 \mu \mathrm{L}$ of carbonate buffer $0.1 \mathrm{M}$ $\mathrm{pH} 8.5$ and $600 \mu \mathrm{l}$ of 5(6)-Carboxyfluorescein N-hydroxysuccinimide ester 0.17 $\mathrm{mg} \mathrm{mL}^{-1}$ in DMSO. For poly(Glu:Lys:Tyr, 6:3:1), $3 \mathrm{~mL}$ of the polypeptide of 2 $\mathrm{mg} \mathrm{mL}^{-1}$ were mixed with $300 \mu \mathrm{L}$ of carbonate buffer $0.1 \mathrm{M} \mathrm{pH} 8.5$ and $600 \mu \mathrm{l}$ of 5(6)-Carboxyfluorescein N-hydroxysuccinimide ester $1 \mathrm{mg} \mathrm{mL}^{-1}$ in DMSO. The mixtures were allowed to react for $1 \mathrm{~h}$ at room temperature in continuous stirring and in darkness. The excess of unbound fluorescein was removed by filtration and 
washing in Microcon filters (Millipore) of $3 \mathrm{KDa}$. The chemically modified polypeptide was suspended in distilled water to obtain a final concentration of 2 $\mathrm{mg} \mathrm{mL}^{-1}$ of the polypeptide. Then, SWCNTs were functionalized with the chemically modified polypeptides. In this procedure, $1 \mathrm{mg}$ of SWCNTs was mixed with $0.15 \mathrm{~mL}$ of the chemically modified polypeptide of $2 \mathrm{mg} \mathrm{mL}^{-1}$ and $0.85 \mathrm{~mL}$ of distilled water. The mixture was ultrasonicated in a Soniprep for $40 \mathrm{~s}$ (4 cycles of $10 \mathrm{~s}$ on and $10 \mathrm{~s}$ off) and then sonicated for $2 \mathrm{~h}$ in water bath $(3 \mathrm{~W})$ at room temperature. The suspension was then centrifuged at $13200 \mathrm{rpm}$ for 10 minutes and the supernatant was pippeted off. Excess of polypeptide was removed by ultrafiltration in tubes of $100 \mathrm{kDa}$ and washing the retentate 3 times with distilled water. The functionalized SWCNTs were suspended in $1 \mathrm{~mL}$ of distilled water.

Functionalization of SWCNTs with proteins. $1 \mathrm{mg}$ of SWCNT was mixed with $1 \mathrm{~mL}$ of the protein of $0.5 \mathrm{mg} \mathrm{mL}^{-1}$ in bidistilled water and the mixture was ultrasonicated in a Soniprep for $40 \mathrm{~s}$ ( 4 cycles of $10 \mathrm{~s}$ on and $10 \mathrm{~s}$ off) and then sonicated for $2 \mathrm{~h}$ in water bath $(3 \mathrm{~W})$ at room temperature. The suspension was applied to ultrafiltration tubes of $100 \mathrm{kDa}$, ultrafiltrated and washed 3 times with $50 \mu \mathrm{L}$ of distilled water to collect the unbound protein. The concentration of bound protein is determined indirectly after determining the concentration of unbound protein in the filtrate. The concentration of protein in the filtrate was determined by the Bio-Rad DC Protein Assay. Calibration curves were obtained by preparing solutions of the different proteins (albumin, trypsin, pepsine, lysozime, ferritin, fibrinogen, papain and hemoglobin) from 0.2 to $1.5 \mathrm{mg} \mathrm{mL}^{-1}$. The protein concentration was calculated after interpolation with the calibration curve. 
Molecular absorption spectroscopy. Molecular absorption spectra were recorded in a Thermo He $\lambda$ ios $\alpha$ spectrophotometer using a $1 \mathrm{~cm}$ optical pathway quartz cuvette.

Dichroism circular spectroscopy. The spectra were recorder in a Chirascan dichroism circular spectrometer using a $1 \mathrm{~cm}$ optical pathway quartz cuvette.

Agarose gel electrophoresis. $0.8 \%$ agarose gel electrophoresis in TAE buffer was used to study the interaction of plasmid DNA with functionalized carbon nanotubes. The gel was run for $45 \mathrm{~min}$ at $90 \mathrm{~V} .40 \%$ sucrose was used as loading buffer for the plasmid DNA-functionalized SWCNTs complexes. A $10 \mu \mathrm{L}$ sample was charged in each well prepared by mixing $8 \mu \mathrm{L}$ of the complexes with $2 \mu \mathrm{L}$ of loading buffer. Ethidium bromide was used for DNA staining.

Confocal microscopy. HeLa cells were grown in cover slips in 6-well plates overnight $\left(3 \times 10^{5}\right.$ cells were seeded per well in $2 \mathrm{~mL}$ of media (DMEM supplemented with $10 \%$ Bovine Fetal Serum, 1\% non-essential amino acids and 1 $\%$ penicillin and streptomycin)). After removing the old media and washing with PBS, $2 \mathrm{~mL}$ of Opti-MEM Reduced Serum Media containing the functionalized SWCNTs with polypeptides chemically modified with fluorescein were added and incubated with the cells for 1 to $3 \mathrm{~h}$. Then, the cover slip was removed from the growth medium and washed twice with PBS. After fixation with paraformaldehyde $3.7 \%$ in PBS for $10 \mathrm{~min}$, the cells were washed twice with PBS and then they were equilibrated for 5 minutes in the slowfade equilibration buffer. After removing the equilibration buffer, one drop of the slowfade reagent was added to the slip and, finally, the cover slip was mounted on a slide.

Elucidation of the mechanism of entry of functionalized SWNTs in mammalian cells. Cells were seeded in 96 -well plates at $2 \times 10^{4}$ cells in $200 \mu \mathrm{L}$ of media. After growing the cells overnight, cells were preincubated during 30 minutes at $37{ }^{\circ} \mathrm{C}$ 
with the following solutions: a) PBS as control, b) azide $10 \mathrm{mM}$ to inhibit endocytosis, c) sucrose $0.45 \mathrm{M}$ in PBS to inhibit chlathrin endocytic pathway, d) filipin $5 \mu \mathrm{g} \mathrm{mL}^{-1}$ and nystatin $10 \mu \mathrm{g} \mathrm{mL}^{-1}$ in PBS to inhibit caveolae endocytic pathway. Then, $200 \mu \mathrm{L}$ of Opti-MEM Reduced Serum Media containing the functionalized SWCNTs with polypeptides chemically modified with fluorescein were added and incubated with the cells for $3 \mathrm{~h}$. All the experiments were carried out in triplicates. Then, the media was removed and the cells were washed three times with PBS. $25 \mu \mathrm{L}$ of lysis buffer was added to each well and the plates were incubated for 20 minutes on a rocking platform. The fluorescence of the lysates was measured on a well plate reader using $485 \mathrm{~nm}$ as excitation wavelength and $535 \mathrm{~nm}$ as emission wavelength.

\section{RESULTS AND DISCUSSION}

\subsection{DISPERSION OF SWCNTS WITH AMPHIPHILIC POLYPEPTIDES}

\subsubsection{Effects of amphiphilic polypeptide characteristics on the dispersion properties of SWCNTS.}

Random peptide copolymers were tested to disperse SWCNTs. These copolymers are polypeptides that contain two kinds of side chains, one hydrophobic and one hydrophilic, in a defined hydrophilic:hydrophobic side chain ratio (see figure 1). These peptides disperse SWCNTs through the interaction between the carbon nanotube sidewall and the hydrophobic side chains, and the presence of the hydrophilic groups from the peptide on the wrapped carbon nanotube that render them dispersed in water. To optimize SWCNT binding and functionalization with these peptides we investigated the interaction of SWCNTs with designed polypeptides with controlled proportions of aromatic residues (tryptophan (Trp), 
tyrosine (Tyr) and phenylalanine (Phe)) and hydrophilic groups (lysine (Lys), arginine (Arg) and ornithine (Orn)). Dispersion curves were obtained for designed polypeptides using different SWCNT:polypeptide ratios by keeping constant the concentration of the polypeptide $\left(0.3 \mathrm{mg} \mathrm{mL}^{-1}\right)$ and changing the concentration of SWCNTs in the sonication mixture (from 0.15 to $1.8 \mathrm{mg} \mathrm{mL}^{-1}$ ). The absorbance value of the dispersed mixture in the NIR region was used as a measurement of the concentration of dispersed SWCNTs. $730 \mathrm{~nm}$ was selected as working wavelength given that the functionalized SWCNTs have a spectral maximum at this wavelength and it is not interfered by the polypeptide absorption. The molar extinction coefficients at this wavelength for the polypeptide wrapped SWCNTs were used to calculate the concentration of dispersed SWCNTs are described in the Online Resource 1. A typical dispersion curve is shown in figure 2. As a general trend, there is an optimum SWCNT:polypeptide ratio in the dispersion mixture where a maximum concentration of dispersed SWCNTs is obtained. Above this optimum, the concentration of dispersed nanotubes decreases. This is likely to be due to limiting concentrations of polypeptide being shared between large numbers of SWCNTs such that insufficient active polypeptide is available for dispersing each nanotube. This is reflected in the dispersion yield, which is calculated from the concentration of dispersed SWCNTs and the initial concentration of SWCNTs in the dispersion mixture. As can be seen, the dispersion yield decreases as the initial concentration of SWCNTs increases, as expected. The dispersion curves for all the tested amphiphilic polypeptides were obtained. The optimal conditions for dispersion, in terms of SWCNT:polypeptide ratio, and maximum dispersion yields for all of the tested amphiphilic polypeptides are shown in table 1 . 
Ultrasonication time was also investigated as it is important when SWCNTs are functionalized with peptides. Prolonged ultrasonication times lead to, apart from higher damage on the SWCNT sidewall, high temperatures in the dispersion mixture, denaturalization of the peptides and loss of enzymatic activity. It was found that ultrasonication times up to $40 \mathrm{~s}$ increase the dispersion yield but remain constant thereafter (see Online Resource 2).

The effect of the composition of the amphiphilic polypeptide on the dispersion yield was studied. In figure 3 the effect of the hydrophilic group, the aromatic group and the hydrophilic:hydrophobic side chain ratio is shown. As can be seen, the solubilization yield decreases in the sequence Orn $->$ Lys $->$ Arg. This sequence corresponds to the size of the linker between the $\alpha$-carbon and the amine group in the amino acid side chain and suggests that decreasing the size of the linker optimizes solubilisation yield. It seems likely that the shorter hydrophilic chains form more compact micelles that are more efficient at solubilising the SWCNTs. The solubilisation yield is shown to decrease in the sequence Phe -> Trp -> Tyr, which corresponds to increasing hydrophobicity of the aromatic side chains. This can be explained by the stronger $\pi$-interaction interaction between the aromatic group and the surface of carbon nanotubes that makes the SWCNTpeptide complex more stable in suspension. The effect of the hydrophilic:hydrophobic ratio was also studied using the polymer poly(Lys:Tyr) as a model. As can be seen in figure 3, the optimal ratio was 1: 1 which presumably reflects the need for both hydrophobic (to interact with SWCNTs) and hydrophilic (to interact with solvent) groups for optimal solubilisation. 


\subsubsection{Characterization of SWCNTs functionalized with amphiphilic}

polypeptides.

To investigate the molecular interaction between the amphiphilic polypeptides and SWCNTs, the optical properties of the functionalized carbon nanotubes were studied by UV-VIS-NIR molecular absorption. The RNA unwrapping method (see Online Resource 1) was used to obtain these spectra (Jeynes et al. 2006). This method allows the determination of the molar extinction coefficients of each functionalized SWCNTs at different wavelengths. In figure 4A the molecular absorption spectra of different functionalized SWCNTs normalized at $400 \mathrm{~nm}$ are shown with the significant spectral regions expanded. As can be seen, for polypeptide-wrapped SWCNTs peaks at $643,702,723,740,802943,950$ and $1015 \mathrm{~nm}$ appear but the relative intensity of each peak depends on the kind of polypeptide wrapping the SWCNT. It was observed that as the hydrophobicity of the polypeptide increases the peaks at $702,740,943$ and $1015 \mathrm{~nm}$ are more enhanced (Online Resouce 1). This can be explained by the electron filling of the empty states of semiconducting and metallic nanotubes by the increased amount of aromatic groups, with a higher electron delocalization (Britz and Khlobystov 2006). This effect strongly depends on the hydrophobic:hydrophilic side chain ratio of the polypeptide interacting with carbon nanotube surface. The functionalized SWCNTs were also characterized by circular dichroism (CD). The study of circular dichroism of functionalized SWCNTs is of high importance as it has been scarcely studied with few studies in the literature (Heller et al. 2006; Dukovic et al. 2006; Peng et al. 2007). In figure 4B the CD spectra of the SWCNTs functionalized with different amphiphilic polypeptides are shown. The signals in the UV region are ascribed to the secondary $(190-250 \mathrm{~nm})$ and tertiary structures $(250-350 \mathrm{~nm})$ of the polypeptides wrapping the SWCNTs (see Online 
Resouce 3). From these bands the structure adopted by the polypeptides when wrapping the SWCNTs could be obtained given that the features in the CD spectra are related to the secondary and tertiary structure of proteins. As can be seen, the normalized spectra for all the polypeptides are similar indicating similar binding modes for the polypeptides to the SWCNTs. The CD spectra of albumincoated SWCNTs, in which albumin probably adopts a globular conformation on SWCNTs was also obtained for comparison. As can be seen, the spectral features are very similar indicating that these polypeptides probably adopt a "beads-on-astring" binding geometry when attached to SWCNTs, as is has been reported from AFM analysis (Matsuura et al. 2006). In figure 4C the AFM image of SWCNTs wrapped with poly(Lys:Phe, 1:1) is shown, where the wrapping with the peptide adopting globular structures around the nanotube is apparent. The most interesting feature found on the CD spectra of these functionalized SWCNTs is the band at around $500 \mathrm{~nm}$. The band at around $500 \mathrm{~nm}$ can be ascribed to SWCNTs optical bands that become CD-active after wrapping with chiral surfactants as these polypeptides. As can be seen, the CD bands have different intensity depending on the polypeptide wrapping the SWCNTs. As SWCNTs are in a racemic mixture, this band can be ascribed to an induced $\mathrm{CD}$ that is the quantum mechanical coupling of the transition dipole moments of SWCNTs and the polypeptides.

\subsection{APPLICATIONS OF SWCNTS FUNCTIONALIZED WITH AMPHIPHILIC POLYPEPTIDES}

The functionalization of SWCNTs with amphiphilic polypeptides described here was applied for the development of a model for the characterization of the binding of natural proteins to carbon nanotubes. Furthermore, the functionalization of SWCNTs with cationic amphiphilic polypeptides can be used 
as a platform for the binding of DNA to carbon nanotubes. These applications will be described in the following sections.

\subsubsection{Modeling the use of SWCNTs as protein carriers.}

In general, proteins are thought to interact with carbon nanotube surface through multiple non-specific interactions but, given the complexity of protein structure, the mechanism of binding has not yet been solved (Salzmann et al. 2008). The principle means by which proteins are thought to adsorb to the hydrophobic surface of carbon nanotubes is through $\pi-\pi$ stacking interaction between aromatic amino acids side chains and the $\pi$-electron system of the SWCNTs, and also through van der Waals interactions. The ability of proteins to disperse SWCNTs is thought to be due to their hydrophilic residues being able to interact with the solvent to create micelle-like structures. However, there has not been a detailed study of the binding properties of proteins to carbon nanotubes that could predict their efficiency in dispersing carbon nanotubes. In this work, we applied the conclusions derived from the dispersion properties of carbon nanotubes with amphiphilic polypeptides to construct a model that describes the properties of proteins that determine their ability in dispersing carbon nanotubes. Different proteins were tested in their ability to disperse SWCNTs: albumin, trypsine, pepsine, lysozyme, ferritin, fibrinogen, papain and hemoglobin. In figure 5 the relative dispersion yield of SWCNTs for the proteins tested are shown. As can be seen, proteins disperse SWCNTs with a different efficiency. In order to model the dispersion properties of natural proteins, several parameters that describe protein composition and structure were selected according to the dispersion results obtained with amphiphilic polypeptides. When plotting the dispersion yield of proteins as a function of these parameters different conclusions can be obtained. 
Firstly, the hydrophilic:hydrophobic side chain ratio and the number of aromatic amino acids determine the dispersion properties of proteins by means of the percentage of aromatic amino acids and the percentage of hydrophobic amino acids. As the hydrophobic content is increased, lower amount of SWCNT are dispersed. As can be seen in figure 5, as the hydrophobicity of the protein increases the amount of protein attached to the SWCNTs increases, but owing to protein hydrophobicity the functionalized SWCNTs agglomerate and precipitate. The results obtained with the amphiphilic polypeptides indicates that aromaticity content also influences the ability of proteins to disperse SWCNTs. As can be seen in figure 5, there is an optimum aromatic content for the best dispersion properties of SWCNTs. Furthermore, the isoelectric point of the protein plays an important role in the dispersion properties. The isoelectric point (PI) is related to the number of acidic (negatively charged) amino acids and basic (positively charged) amino acids being proteins less charged in water when the $\mathrm{pH}$ is proximal to the isoelectric point. As the dispersion properties of proteins were tested at neutral $\mathrm{pH}$, the difference from this $\mathrm{pH}$ value and the isoelectric point of the proteins determines their degree of ionization: the higher the difference the higher the degree of ionization. As the degree of ionization increases, the ability to disperse carbon nanotubes also increases due to the increased density of polar ionized groups around the carbon nanotube-protein complex. As can be concluded from figure 5, the data can be plotted to obtain optimal values for hydrophilic:hydrophobic radio, aromaticity content and pI values for SWCNTs dispersion by proteins. The values can therefore be used to optimize binding of proteins to SWCNTs in fields such as biosensing and protein delivery vectors. 


\subsubsection{Applications of SWCNTs functionalized with cationic amphiphilic polypeptides as gene carriers.}

As an application of the SWCNTs functionalized with amphiphilic polypeptides, we tested them as gene carriers. Cationic amphiphilic polypeptides were used for these purposes given their ability to bind negatively charged DNA by ionic interactions. The binding of plasmid DNA to functionalized SWCNTs was studied by agarose gel electrophoresis, using for this study the pGL3 plasmid which encodes the gene luciferase whose expression can be easily assayed. It has previously been demonstrated that ethidium bromide cannot intercalate with plasmid DNA bound to functionalized SWCNTs (Singh et al. 2005), as the DNA is in a condensed form. Therefore, the amount of free DNA (not bound to SWCNTs) can be thereby estimated from the gel by measuring the quantity of DNA than can be detected by ethidium bromide staining. Several functionalized SWCNT:DNA complexes were prepared for each polypeptide at different ratios in order to determine the amount of bound DNA. The amount of plasmid DNA bound to carbon nanotubes at several dilutions was estimated by incubating polypeptide-SWCNT complexes with plasmid followed by gel electrophoresis. After running the gel, the amount of bound plasmid per mass of polypeptideSWCNT was determined by reference to the lane with the highest dilution of polypeptide-SWCNTs at which no free DNA was detectable (see figure 6, there is a saturating amount of plasmid DNA on functionalized SWCNTs at this concentration). It was observed that the properties of the amphiphilic polypeptide wrapping the SWCNTs have a profound effect on the plasmid DNA binding properties. As can be seen in table 2, the nature of cationic side chain of the polypeptide affects DNA binding properties, increasing the efficiency of binding in the sequence Arg-Orn-Lys. This can be explained by the higher density of 
cationic groups with lysine- and ornithine-containing polypeptides than argininecontaining polypeptides. The length of the side chain may also play an important role on the condensation properties of DNA on the functionalized SWCNTs. As the lysine side chain is longer than ornithine, the structure is more flexible and porous and may allow a better intercalation of the plasmid DNA in the cationic group attached to the carbon nanotube. As can be seen also in table 2, the aromatic group plays an important role in the DNA condensation properties with increasing hydrophobicity increasing DNA binding. This could be due to increased hydrophobicity of aromatic group leading to stronger interaction with the SWCNT and thereby binding a higher amount of polypeptides with higher density of cationic groups available for DNA binding. The effect of the hydrophilic:hydrophobic side chain ratio on the DNA binding properties was also investigated using poly(Lys:Tyr) polypeptides. As can be seen in table 2, binding of plasmid DNA is enhanced by increased amount of hydrophilic groups of the polypeptide, presumably leading to a higher density of cationic groups available for DNA binding. From these studies can be deduced that the best conditions for plasmid DNA binding are obtained with a polypeptide with a hydrophilic:hydrophobic side chain ratio of $4: 1$, lysine as cationic group and phenylalanine as aromatic group.

\subsubsection{Applications of functionalized SWCNTs as protein and gene delivery systems.}

As was described in the previous sections, SWCNTs can be used as peptide and gene carriers. In this section, we sought to investigate how the protein parameters investigated above affect SWCNT uptake using HeLa cells as a model. The internalization of nanotubes in the cells was followed by confocal microscopy using SWCNTs functionalized with a polypeptide chemically modified (CMP) 
with fluorescein (CMP-SWCNTs). Owing to the excellent properties of dispersion and DNA binding of poly(Lys:Phe, 1:1), this polypeptide was selected to study the internalization of these functionalized SWCNTs in the cells. As can be seen in figure 7A-C, SWCNTs enhance the internalization of the polypeptide in the cells, indicating that the SWCNTs can be used to deliver cargoes into cells. After $1 \mathrm{~h}$ of incubation the CMP-SWCNTs are already internalized in the cells and after the 3 $\mathrm{h}$ it was observed that CMP-SWCNTs have accumulated in the cytoplasmic region near the nuclear envelope (see Online Resource 4). The mechanism of entry was investigating using endocytosis inhibition conditions. Cells were preincubated in endocytosis inhibiting conditions before incubation with CMPSWCNTs: azide for endocytosis inhibition, sucrose for clathrin endocytic pathway inhibition and nystatin and filipin for caveolae endocytic pathway inhibition. The degree of internalization was quantified by the measurement of the fluorescence of the lysate after incubation with the CMP-SWCNTs. As can be seen in figure 7D, endocytosis inhibition decreased internalization of the SWCNTs indicating that internalization involved endocytosis. We next investigated the influence of attachment of plasmid DNA on particle uptake. Plasmids are negatively charged and therefore increasing plasmid binding will lead to the SWCNT particles going from positively to neutral and then negatively charged, as can be seen in Online Resource 5. The complexes of CMP-SWCNTs with DNA were incubated with HeLa cells and their internalization was quantified by the measurement of the fluorescence in the lysate. Complexes positively charged or neutral were effectively delivered in the cells, obtaining a maximum of efficiency of internalization for neutral complexes. However, negatively charged complexes are less efficiently delivered to the cells. It is likely that the electrostatic repulsion with the negatively charged cell membrane inhibits uptake. Also, neutral DNA- 
CMP-SWCNT complexes may diffuse through the hydrophobic lipid bilayer of the cell membrane. The influence of charge on uptake was confirmed by studying the internalization of SWCNTs wrapped with amphiphilic polypeptides. As can be seen in figure 7D, SWCNTs wrapped with a negatively charged peptide were internalized with a lower efficiency than SWCNTs wrapped with positively charged peptides. This effect of the global charge of the functionalized SWCNTs therefore plays an important role in optimising conditions for the use of carbon nanotubes as protein and DNA delivery systems.

\section{CONCLUSIONS}

In this paper, the ability of various amphiphilic polypeptides to disperse SWCNTs was examined. From this study is was concluded that the binding and dispersion properties of proteins is influenced by the nature of aromatic groups, hydrophilic groups and the hydrophilic:hydrophobic side chain ratio. The findings were used to develop a simple model to predict the SWCNT adsorption and dispersion properties of natural proteins. This model was based on properties that describe the protein structure and composition. The optical properties of the polypeptideSWCNT complexes were studied such as molecular absorption spectroscopy and circular dichroism, showing that these properties depend on the polypeptide wrapping the SWCNTs. Finally, the DNA-binding capacity of various functionalized SWCNTs with cationic amphiphilic polypeptides was examined and optimal conditions determined for gene delivery. Uptake of SWCNTs carrying peptides and plasmid DNA was shown to be via the endocytic pathway and the global charge of the complex was shown to play an important role in the efficiency of uptake. 
ACKNOWLEDGMENTS. This work has been performed in the framework of the FP6Marie Curie Research Training Network “CARBIO” (RTN-CT-2006-035616) funded by the European Union. We also acknowledge funding received from the EPSRC Portfolio Partnership award.

\section{REFERENCES}

Besteman K, Lee JO, Wiertz FGM, Heering HA, Dekker C (2003) Enzyme-coated carbon nanotubes as single-molecule biosensors. Nano Let 3:727-730.

Bianco A, Kostarelos K, Prato M (2005) Applications of carbon nanotubes in drug delivery. Curr Opin Chem Biol 9:674-679.

Britz DA, Khlobystov AN. Noncovalent interactions of molecules with single walled carbon nanotubes. Chem Soc Rev 2006; 35:637-59.

Chen RJ, Bangsaruntip S, Drouvalakis KA, Kam NWS, Shim M, Li Y, et al (2003) Noncovalent functionalization of carbon nanotubes for highly specific electronic biosensors. PNAS 100:49844989.

Chen RJ, Zhang Y, Wang D, Dai H (2001) Noncovalent sidewall functionalization of singlewalled carbon nanotubes for protein immobilization. J Am Chem Soc 123:3838-3839.

Dukovic G, Balaz M, Doak P, Berova ND, Zheng M, Mclean, RS, et al. (2006) Racemic singlewalled carbon nanotubes exhibit circular dichroism when wrapped with DNA. J Am Chem Soc 128:9004-9005.

Enyashin AN, Gemming S, Seifert G (2007) DNA-wrapped carbon nanotubes. Nanotechnology $18: 245702$

Heister E, Neves V, Tîlmaciu C, Lipert K, Sanz Beltrán V, Coley HM, et al. (2009) Triple functionalisation of single-walled carbon nanotubes with doxorubicin, a monoclonal antibody, and a fluorescent marker for targeted cancer therapy. Carbon 47:2152-2160.

Heller DA, Jeng ES, Yeung TK, Martinez BM, Moll AE, Gastala JB, et al. (2006) Optical detection of DNA conformational polymorphism on single walled carbon nanotubes. Science 311:508-511.

Huang W, Taylor S, Fu K, Lin Y, Zhang D, Hanks TW, et al. (2002) Attaching proteins to carbon nanotubes via diimide-activated amidation. Nano Lett 2:311-314.

Jeynes JCG, Mendoza E, Chow DCS, Watts PCP, McFadden J, Silva SRP (2006) Generation of Chemically Unmodified Pure Single-Walled Carbon Nanotubes by Solubilizing with RNA and Treatment with Ribonuclease A. Adv Mater 18:1598-1602.

Ju SY, Kopcha WP, Papadimitrakopoulos F (2009) Brightly Fluorescent Single-Walled Carbon Nanotubes via an Oxygen-Excluding Surfactant Organization. Science 323:1319-1323.

Karajanagi SS, Yang H, Asuri P, Sellito E, Dordick JS, Kane RS (2006) Protein-assisted solubilization of single-walled carbon nanotubes. Langmuir 22:1392-1395.

Kim SN, Rusling JF, Papadimitrakopoulos F (2007) Carbon Nanotubes for Electronic and Electrochemical Detection of Biomolecules. Adv Mater 19: 3214-3228.

Klumpp C, Kostarelos K, Prato M, Bianco A (2006) Functionalized carbon nanotubes as emerging nanovectors for the delivery of therapeutics. Biochim Biophys Acta 1758:404-412. 
Kurppa K, Jiang H, Szilvay GR, Nasibulin AG, Kauppinen EI, Linder MB (2007). Controlled hybrid nanostructures through protein-mediated noncovalent functionalization of carbon nanotubes. Angew Chem Int Ed 46:6446-6449.

Liu Z, Tabakman S, Welsher K, Hongjie Dai H (2009) Carbon Nanotubes in Biology and Medicine: In vitro and in vivo Detection, Imaging and Drug Delivery. Nano Res 2:85-120. Ziegler KJ (2005) Developing implantable optical biosensors. TRENDS in Biotech 23 (9):440444.

Matsuura K, Saito T, Okazaki T, Ohshima S, Yumura M, Iijima S (2006) Selectivity of watersoluble proteins in single-walled carbon nanotube dispersions. Chem Phys Lett 429:497-502. Pantarotto D, Partidos CD, Graff R, Hoebeke J, Briand JP, Prato M, et al. (2003) Synthesis, Structural Characterization, and Immunological Properties of Carbon Nanotubes Functionalized with Peptides. J Am Chem Soc 125:6160-6164.

Peng X, Komatsu N, Bhattacharya S, Shimawaki T, Aonuma S, Kimura T, et al. (2007) Optically active single-walled carbon nanotubes. Nat Nanotechnol 2:361-365.

Salvador-Morales C, Flahaut E, Sim E, Sloan J, Green MLH, Sim RB (2006) Complement activation and protein adsorption by carbon nanotubes. Mol Immunol 43:193-201.

Salzmann CG, Lee GKC, Ward MAH, Chu BTT, Green MLH (2008) Highly hydrophilic and stable polypeptide/single-wall carbon nanotube conjugates. J Mater Chem 18:1977-1983.

Salzmann CG, Ward MAH, Jacobs RMJ, Tobias G, Green MLH (2007) Interaction of tyrosine-, tryptophan-, and lysine-containing polypeptides with sigle-wall carbon nanotubes and its relevance for the rational design of dispersing agents. J Phys Chem C 111:18520-18524.

Shim M, Kam NWS, Chen RJ, Li Y, Dai H (2002) Functionalization of carbon nanotubes for biocompatibility and biomolecular recognition. Nano Lett 2: 285-288.

Singh R, Pantarotto D, McCarthy D, Chaloin O, Hoebeke JN, Partidos CD, et al. (2005) Binding and condensation of plasmid DNA onto functionalized carbon nanotubes: toward the construction of nanotube-based gene delivery vectors. J Am Chem Soc 127:4388-4396.

Zorbas V, Ortiz-Acevedo A, Dalton AB, Yoshida MM, Dieckmann GR, Draper RK, Baughman RH, Yacaman MJ, Musselman IH (2004) Preparation and characterization of individual peptidewrapped single-walled carbon nanotubes. J Am Chem Soc 126:7222-7227. 
TABLES.

\begin{tabular}{|c|c|c|c|}
\hline POLYPEPTIDE & $\begin{array}{c}\text { OPTIMAL } \\
\text { SWCNT:POLYPEPTIDE } \\
\text { RATIO }\end{array}$ & $\begin{array}{l}\text { DISPERSED SWCNT } \\
\text { CONCENTRATION }^{\mathrm{a}} \text {, } \\
\mu \mathrm{g} \mathrm{mL}^{-1}\end{array}$ & $\begin{array}{c}\text { OPTIMAL } \\
\text { DISPERSION } \\
\text { YIELD }^{\mathrm{b}}\end{array}$ \\
\hline Poly(Lys:Trp, 4:1) & $3: 1$ & 12.4 & 2.2 \\
\hline Poly(Lys:Tyr, 1:1) & $5: 1$ & 38.4 & 49.4 \\
\hline Poly(Lys:Phe, 1:1) & $1: 2$ & 52.6 & 35.0 \\
\hline Poly(Lys:Tyr, 4:1) & $3: 2$ & 11.8 & 5.8 \\
\hline Poly(Arg:Trp, 4:1) & $5: 1$ & 11.8 & 3.8 \\
\hline Poly(Orn:Trp, 4:1) & $2: 1$ & 18.9 & 3.9 \\
\hline Poly(Lys:Tyr, 1:9) & $1: 2$ & 21.1 & 14.1 \\
\hline Albumin (BSA) & $5: 1$ & 54.0 & 6.7 \\
\hline hemoglobin & $1: 2$ & 5.6 & 3.7 \\
\hline
\end{tabular}

Table 1. SWCNT solubilization properties of the random copolymers. SWCNT:polypeptide ratio is given in w/w; ${ }^{\text {a }}$ solubilized amount of SWCNTs reached at the optimal SWCNT:polypeptide ratio in the solubilization curve; ${ }^{b} \mathrm{SWCNT}$ :polypeptide ratio at which the dispersion yield is maximum (the dispersion yield is calculated by dividing the SWCNT solubilized concentration by the SWCNT initial concentration in the dispersion mixture). SWCNT solubilization properties are given also for the proteins albumin and hemoglobin. 


\begin{tabular}{|c|c|c|}
\hline \multicolumn{2}{|l|}{ POLYPEPTIDE } & $\begin{array}{l}\mu \mathrm{g} \text { DNA. } \mu \mathrm{g}^{-1} \\
\text { polypeptide wrapped } \\
\text { SWCNT }\end{array}$ \\
\hline \multirow{3}{*}{ CATIONIC GROUP } & ARGININE & 2 \\
\hline & ORNITHINE & 8 \\
\hline & LYSINE & 14 \\
\hline \multirow{2}{*}{ AROMATIC GROUP } & PHENYLALANINE & 29 \\
\hline & TYROSINE & 6 \\
\hline \multirow{3}{*}{$\begin{array}{l}\text { HYDROPHILIC:HYDROPHOBIC } \\
\text { SIDE CHAIN RATIO }\end{array}$} & $4: 1$ & 13 \\
\hline & $1: 1$ & 6 \\
\hline & $1: 9$ & - \\
\hline
\end{tabular}

Table 2. DNA binding properties of the functionalized SWCNTs as a function of the cationic group and the hydrophobic:hydrophilic side chain ratio. The effect of the cationic group was performed with an hydrophilic:hydrophobic side chain ratio of 4:1 and Trp as aromatic group; the effect of the aromatic group was performed with an hydrophilic:hydrophobic side chain ratio of 1:1 and Lys as cationic group; the effect of the hydrophilic:hydrophobic side chain ratio was performed with Lys as cationic group and Tyr as aromatic group. 


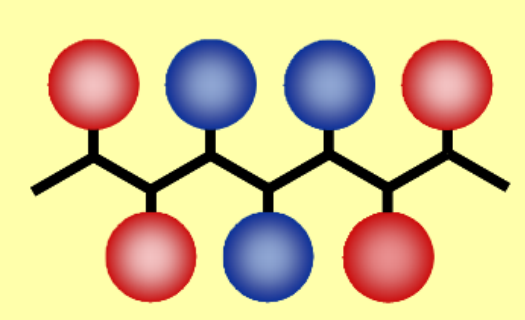

Amphiphilic polypeptide

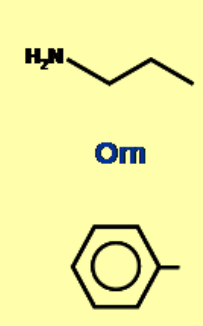

Phe
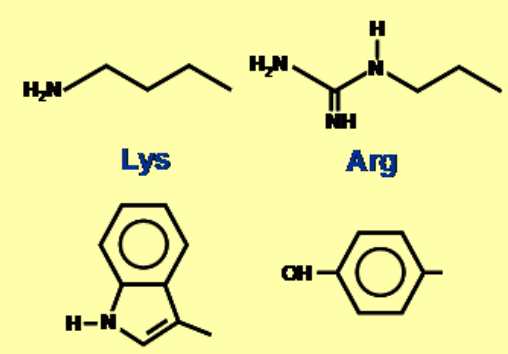

Tip

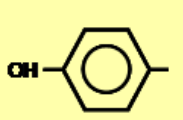

Tyr
A

(a)

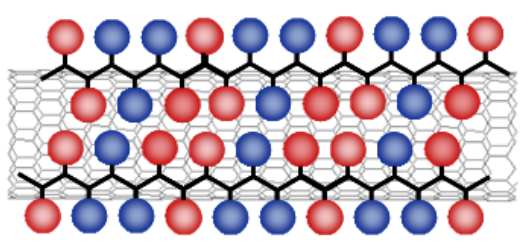

SWCNTs functionalized with amphiphilic polypeptides

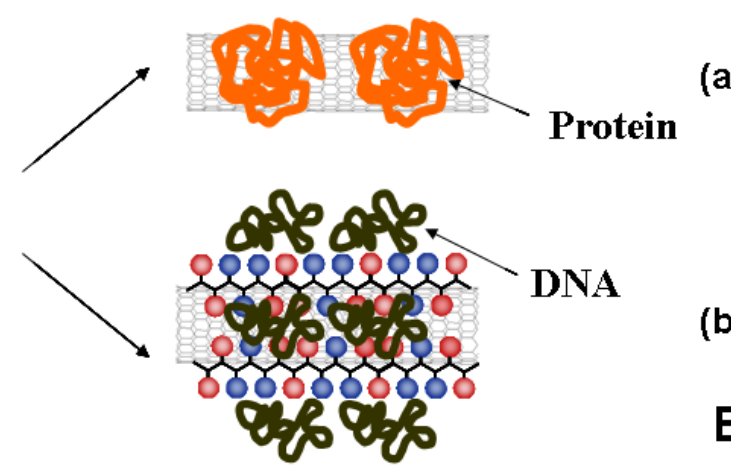

Fig. 1. A) Structure of the amphiphilic polypeptides. These amphiphilic polypeptides contain hydrophobic side chains, (Phe, Trp and Tyr) and cathionic side chains (Orn, Lys and Arg) in a defined hydrophobic:hydrophilic side chain ratio. The following random copolymers were tested: poly(Lys:Trp, 4:1), poly(Lys:Tyr, 1:1), poly(Arg:Trp, 4:1), poly(Lys:Tyr, 4:1), poly(Orn:Trp, 4:1), poly(Lys:Phe, 1:1) and poly(Lys:Tyr, 1:9). B) Structure of SWCNTs functionalized with amphiphilic polypeptides. This procedure models and allows the design of methods of functionalization of SWCNTs with proteins (a). DNA can also be bound to carbon nanotubes by ionic interactions with SWCNTs functionalized with cationic amphiphilic polypeptides (b). 


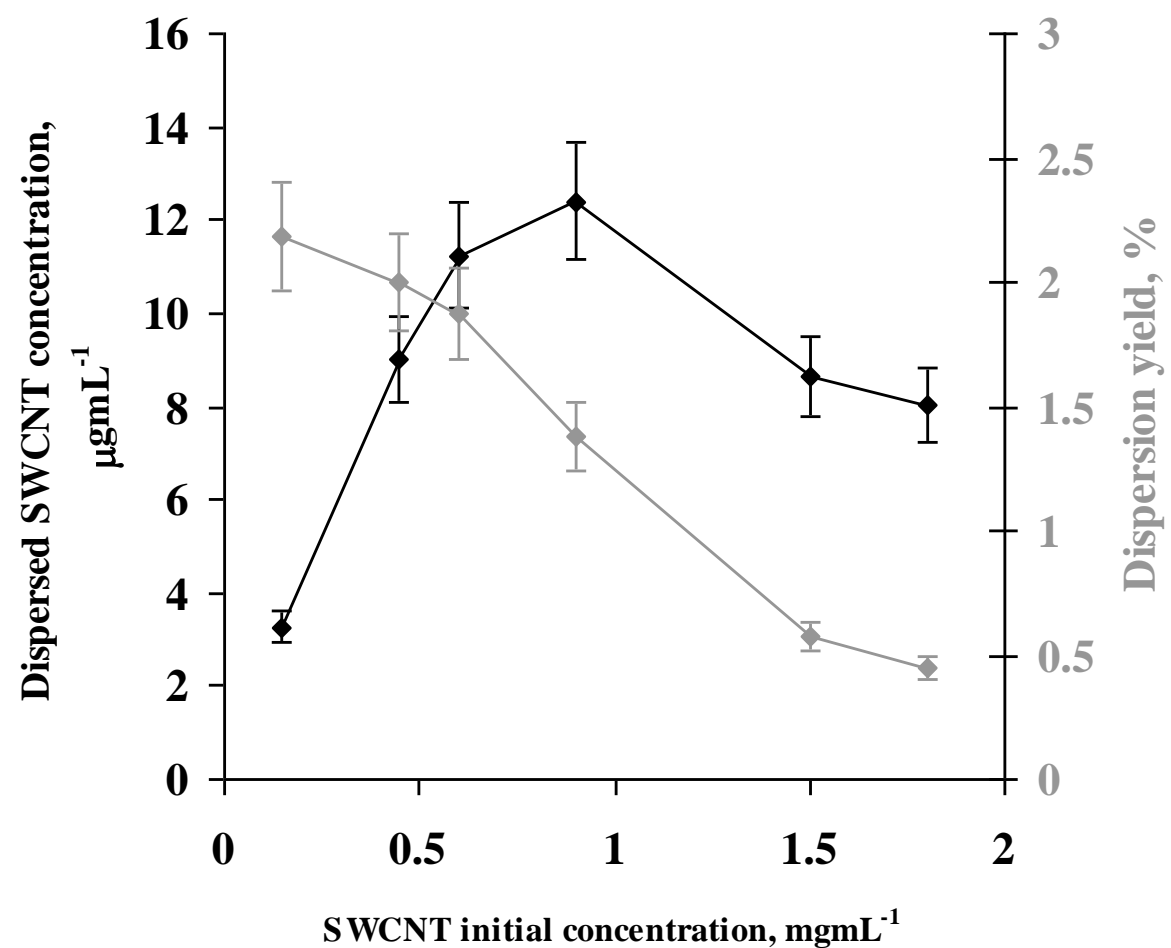

Fig. 2. Typical dispersion curve of SWCNTs with amphiphilic polypeptides. This curve corresponds to SWCNTs dispersion with poly(Lys:Trp, 4:1) at $0.3 \mathrm{mg} \mathrm{mL}^{-1}$. Dispersed SWCNT concentration (black curve) was calculated from the absorption value at $730 \mathrm{~nm}$ of the dispersed solution and the molar extinction coefficient of the functionalized SWCNTs. Dispersion yield (grey curve) was calculated by dividing the dispersed SWCNT concentration by the initial concentration of SWCNTs in the dispersion mixture. 


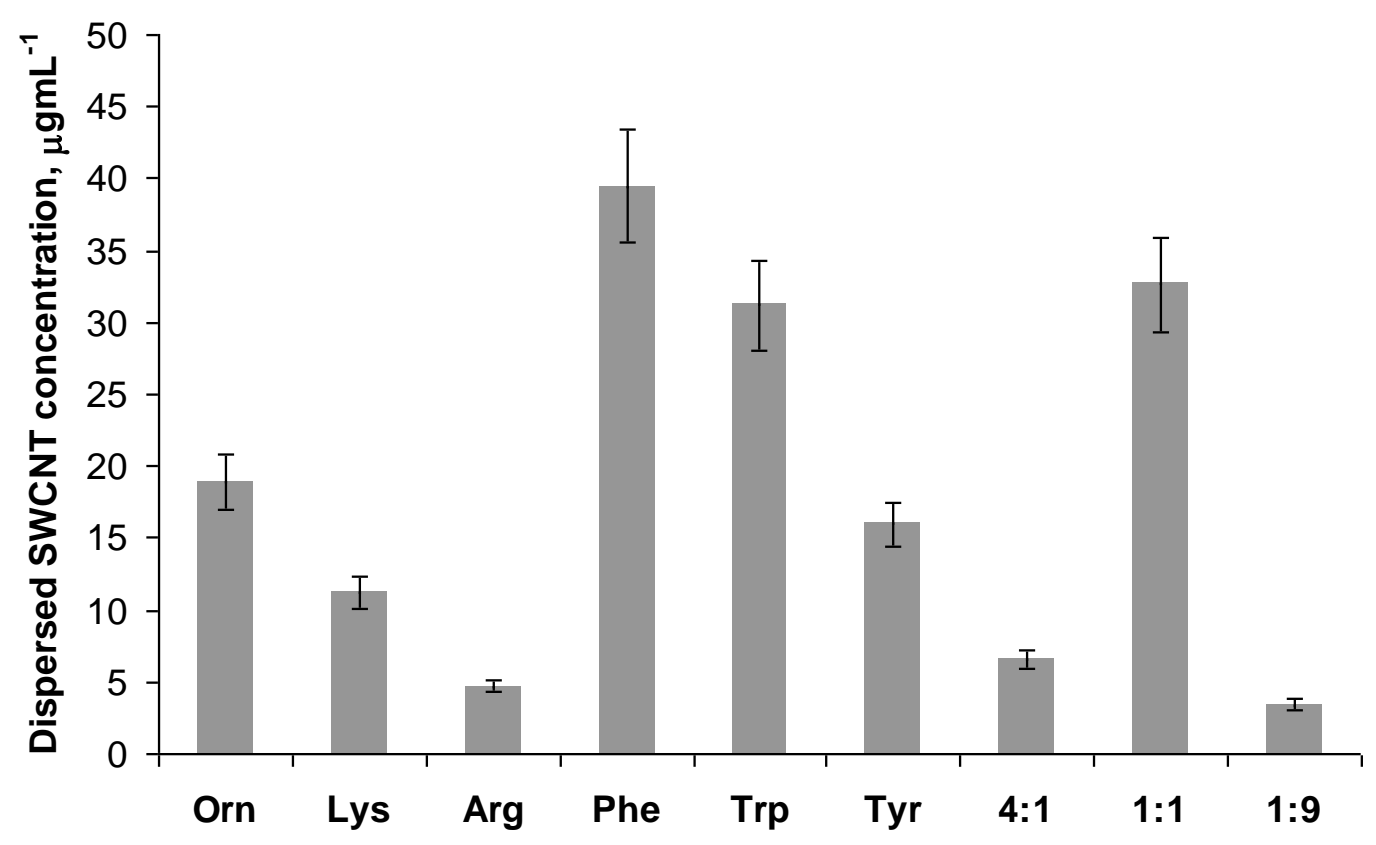

Fig. 3. Effect of the side chains properties and composition of the polypeptide on the dispersion properties of SWCNTs. The relative dispersion was calculated from the absorption value of the dispersion at $730 \mathrm{~nm}$. Black bars: effect of the cationic group of the polypeptide on the SWCNT dispersion properties; the aromatic group in the polypeptide was Trp, the hydrophilic:hydrophobic side chain ratio was $4: 1$, the conditions in the dispersion mixture were $0.6 \mathrm{mg} \mathrm{mL}^{-1}$ of SWCNTs and $0.3 \mathrm{mg} \mathrm{mL}^{-1}$ of polypeptide. Dark grey bars: effect of the aromatic group on the SWCNT dispersion properties; the hydrophilic group was Lys, the hydrophilic:hydrophobic side chain ratio was $1: 1$, conditions in the dispersion mixture were $0.6 \mathrm{mg} \mathrm{mL}^{-1}$ of SWCNTs and $0.3 \mathrm{mg} \mathrm{mL}^{-1}$ of polypeptide; the hydrophaty index is shown in the figure for each of the amino acid side chains. Light grey: effect of the hydrophilic:hydrophobic side chain ratio on the SWCNT dispersion properties; this study was performed with the polypeptide poly(Lys:Tyr) with different Lys:Tyr ratios, the conditions in the dispersion mixture were $0.9 \mathrm{mg} \mathrm{mL}^{-1}$ of SWCNTs and $0.3 \mathrm{mg} \mathrm{mL}^{-1}$ of polypeptide. 

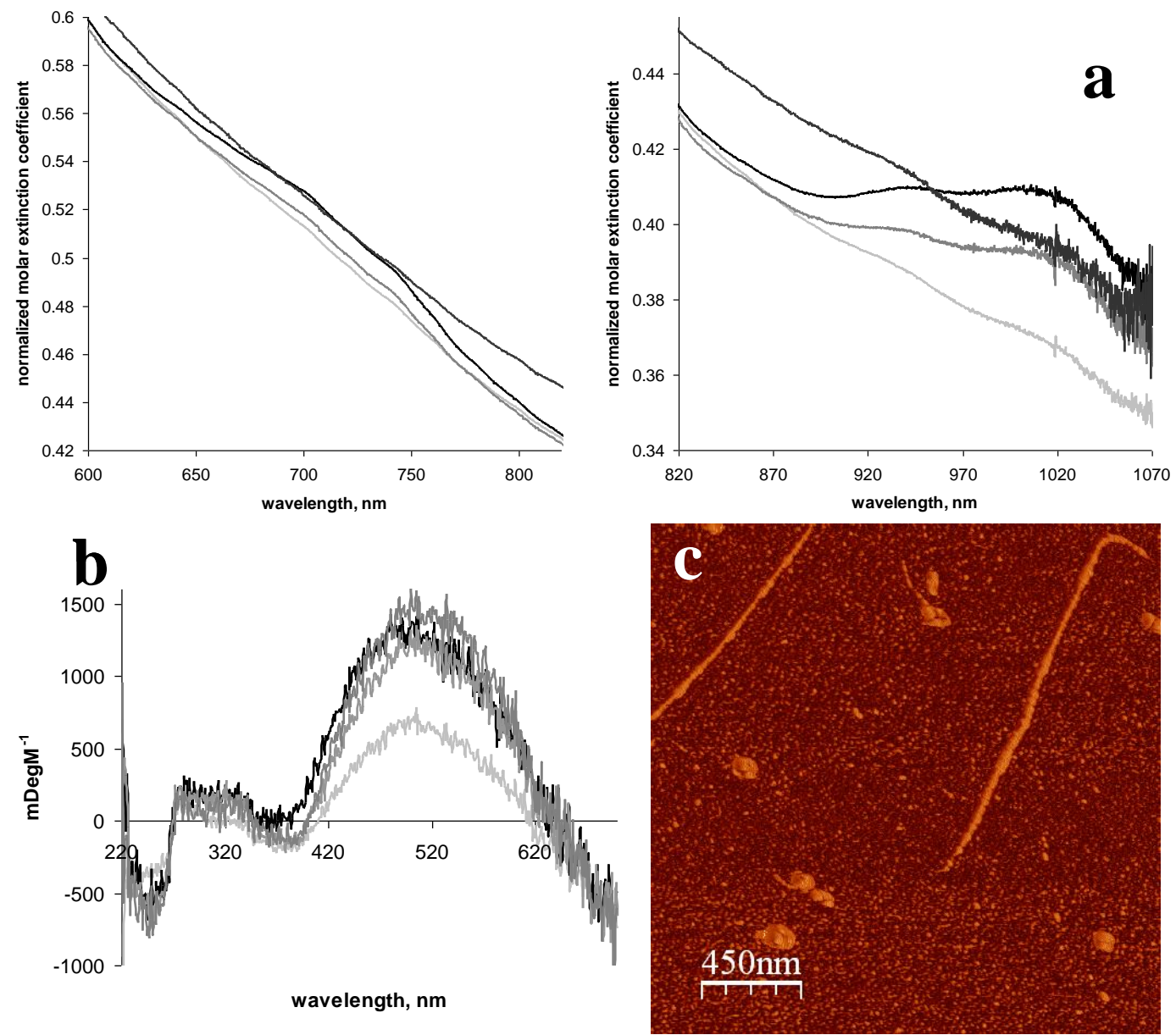

Fig. 4. Characterization of polypeptide-wrapped SWCNTs. A. Normalized molecular absorption spectra of polypeptide-wrapped SWCNTs: - SWCNT-poly(Lys:Tyr,1:1), - SWCNTpoly(Lys:Tyr,4:1), - SWCNT-poly(Lys:Phe,1:1), - SWCNT-poly(Lys:Trp,4:1). Normalization was made at $400 \mathrm{~nm}$. B. Dichroism circular spectra of polypeptide-wrapped SWCNTs. The spectra were normalized by the concentration of functionalized SWCNTs for each sample (-) Poly(Lys:Phe, 1:1), (-) poly(Lys:Tyr, 4:1), (-) poly(Lys:Tyr, 1:1). The DC spectrum for albuminwrapped SWCNTs (-) is also given. C. AFM image of SWCNTs wrapped with poly(Lys:Phe,1:1). 

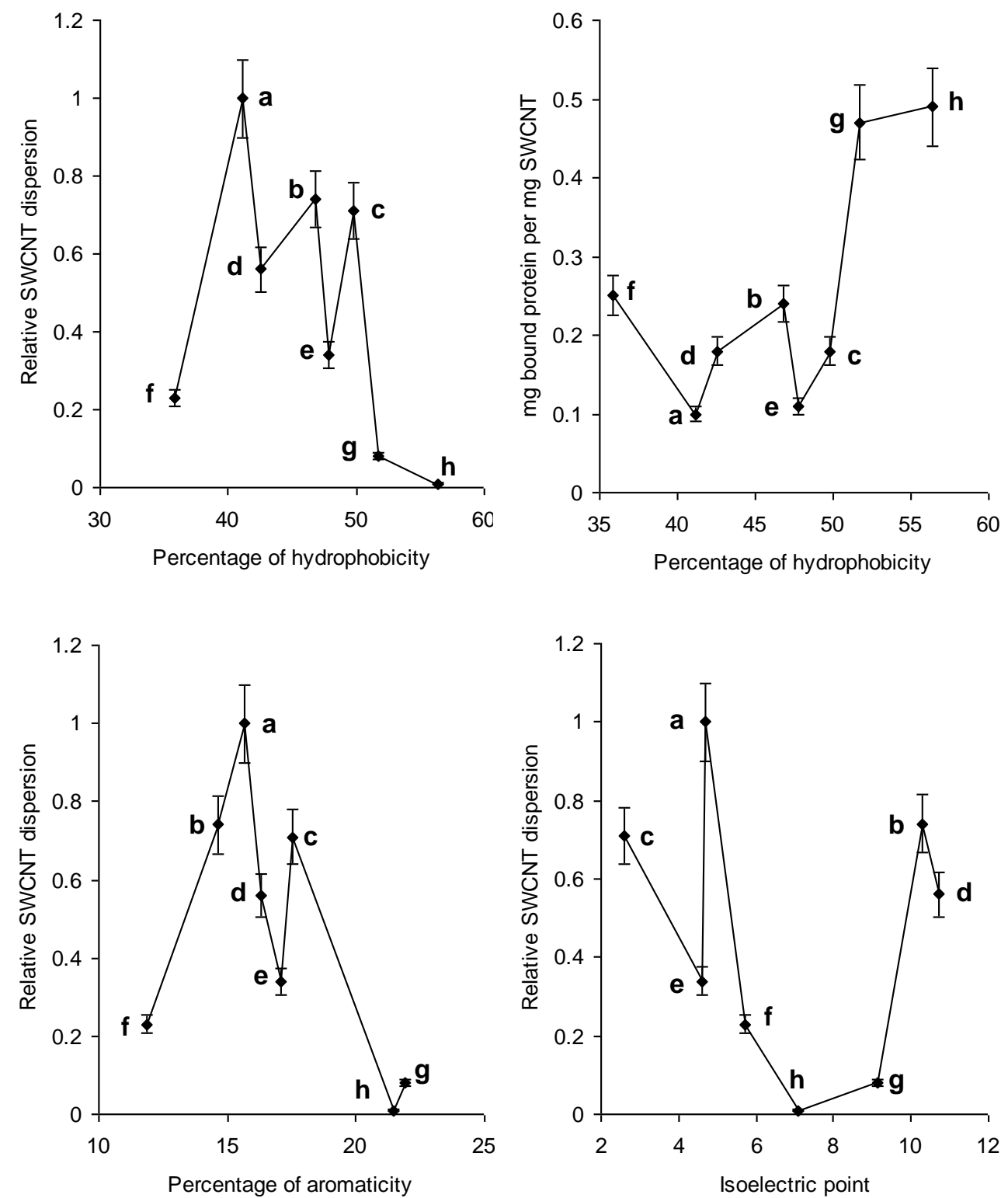

Fig. 5. Parameters that determine the best conditions for the dispersion of SWCNTs with proteins. Tested proteins: a) albumin, b) trypsin, c) pepsine, d) lysozyme, e) ferritin, f) fibrinogen, g) papain and h) hemoglobin. The files selected from Protein Data Bank to calculate the parameters related to the protein structure and composition were as follows: albumin 1BM0, trypsin 1QB1, pepsine 4PEP, Lysozyme 6LYZ, ferritin 1IER, fibrinogen 1JY2, papain 9PAP, hemoglobin 1XZ2. The dispersion efficiencies were normalized by the absorbance value obtained for the protein with the best dispersion properties (albumin). 


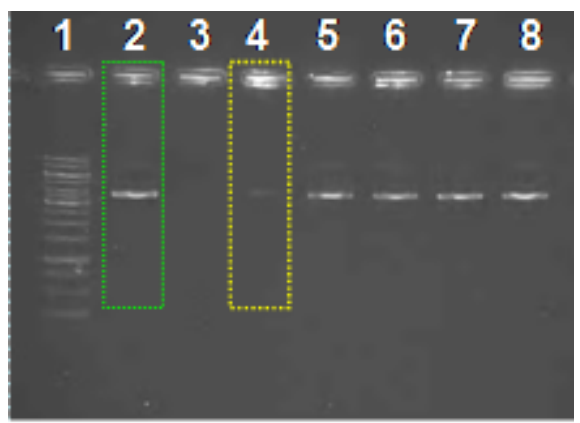

Fig. 6. Agarose gel electrophoresis of functionalized SWCNTs complexed with plasmid DNA. Lane 1: ladder, lane 2: pGL3 plasmid alone 7.12 $\mathrm{ng} \mu \mathrm{L}^{-1}$, lanes 3-8: functionalized SWCNT:plasmid DNA complexes with plasmid $7.12 \mathrm{ng} \mu \mathrm{L}^{-1}$ and different dilutions of functionalized SWCNTs functionalized with poly(Lys:Trp,4:1) (lane 3: $5 \mu \mathrm{g} \mathrm{mL}^{-1}$; lane 4: $0.5 \mu \mathrm{g}$ $\mathrm{mL}^{-1}$; lane 5: $0.05 \mu \mathrm{g} \mathrm{mL}^{-1}$; lane 6: $5 \mathrm{ng} \mathrm{mL}^{-1}$; lane 7: $0.5 \mathrm{ng} \mathrm{mL}^{-1}$; lane 8: $0.05 \mathrm{ng} \mathrm{mL}^{-1}$. The lane 4 shows the lane at which there is not free or partially free plasmid DNA. 

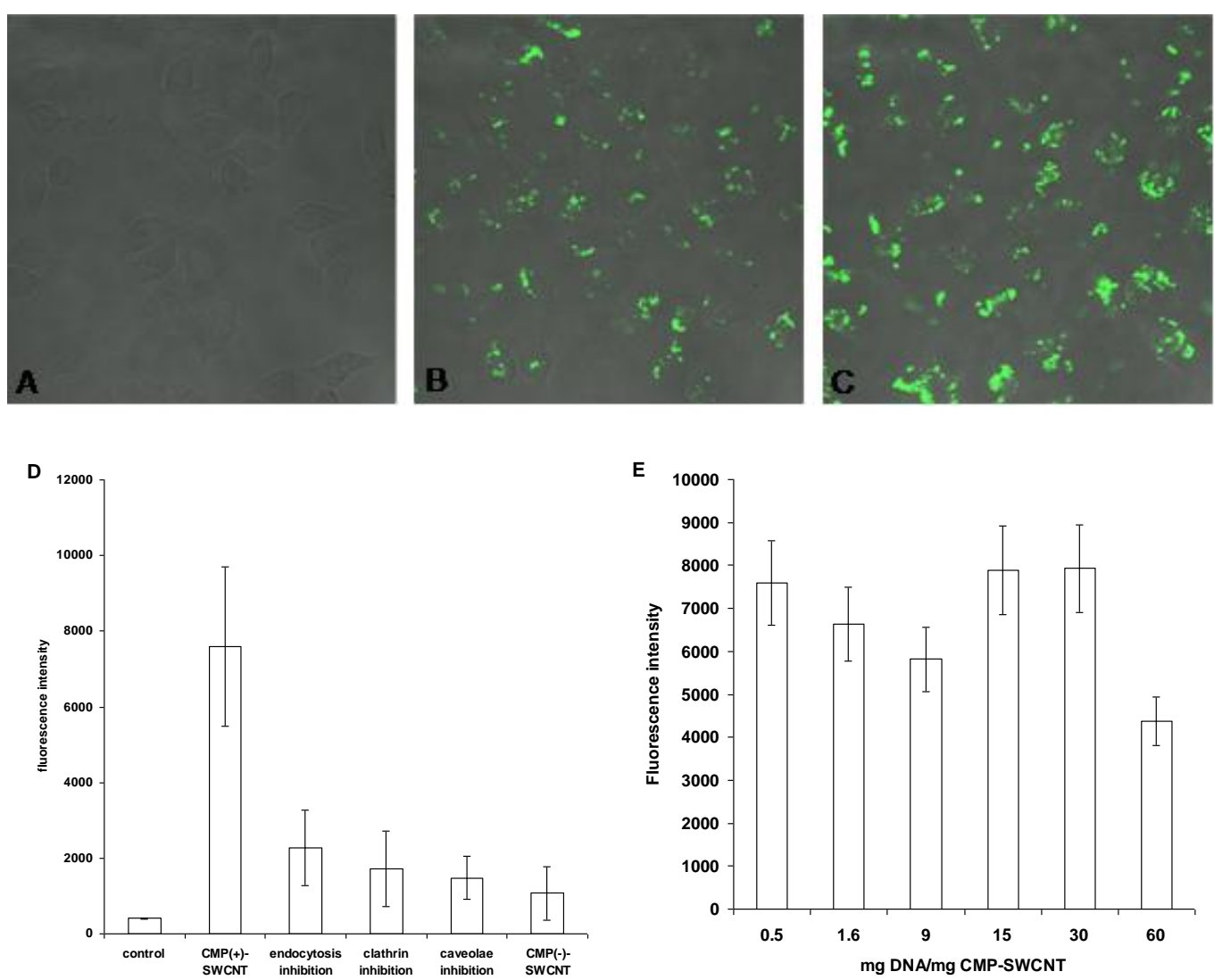

Fig. 7. Confocal images obtained by z-scan of HeLa cells after different incubation conditions: A) control at $37{ }^{\circ} \mathrm{C}$ without CMP or poly(Lys:Phe, 1:1)-fluorescein wrapped SWCNTs, B) control at $37{ }^{\circ} \mathrm{C}$ with poly(Lys:Phe, 1:1)-fluorescein, C) at $37{ }^{\circ} \mathrm{C}$ with poly(Lys:Phe, 1:1)-fluorescein wrapped SWCNTs. D) Elucidation of the mechanism of entry of SWCNTs functionalized with amphiphilic polypeptides. The efficiency of internalization was quantified by the measurement of the fluorescence in the lysate after incubation of HeLa cells with the functionalized SWCNTs. Cells were preincubated in endocytosis inhibiting conditions before incubation with CMP(+)SWCNTs (a positively charged CMP, poly(Lys:Phe, 1:1), was used in these studies): azide for endocytosis inhibition, sucrose for clathrin endocytic pathway inhibition and nystatin and filipin for caveolae endocytic pathway inhibition. The efficiency of internalization of SWCNTs functionalized with a negatively charged CMP (poly(Glu:Lys:Tyr, 6:3:1), CMP(-)-SWCNT) was also studied. The concentration of CMP-SWCNTs was $0.12 \mu \mathrm{g} \mathrm{mL}{ }^{-1}$. E) Effect of DNA/CMPSWCNT ratio on the internalization efficiency. 